\title{
Co-implantation of bone marrow mesenchymal stem cells and chondrocytes increase the viability of chondrocytes in rat osteo-chondral defects
}

\author{
ZHI ZHAO, XINSHE ZHOU, JIANZHONG GUAN, MIN WU and JIANSHENG ZHOU \\ Department of Orthopedics, The First Affiliated Hospital of Bengbu Medical College, \\ Anhui Key Laboratory of Tissue Transplantation, Bengbu, Anhui 233004, P.R. China
}

Received July 19, 2017; Accepted December 22, 2017

DOI: $10.3892 / \mathrm{ol} .2018 .8195$

\begin{abstract}
Replacement of chondrocytes by adult stem cells was believed to improve the performance of autologous chondrocytes transplantation, since less chondrocytes were needed. Previous studies have demonstrated that the increased cartilage production in pellet co-cultures of chondrocytes and bone marrow mesenchymal stem cells (BMSCs) is due to the trophic effects of the MSC by stimulating chondrocyte proliferation and matrix production. However, the destination of MSCs or chondrocytes after implanted in osteo-chondral defects is not clear. The aim of the present study is to investigate the viability of MSCs and chondrocytes after co-implantation into a rat osteo-chondral defect model. MSCs were isolated from bone marrow and chondrocytes were extracted from knee joints of neonatal rats. Results of sulfated glycosaminoglycans (GAG) and collagen quantification demonstrated that co-culture pellets of BMSCs and chondrocytes have more GAG deposition than that of BMSCs or chondrocytes alone. Tracking cells with fluorescence protein demonstrated that MSCs disappeared following co-culture. In a rat knee injury model, co-implantation of BMSCs and chondrocytes contained more viable chondrocytes than chondrocytes implanted alone. To conclude, BMSCs were replaced by chondrocytes in pellet co-culture and BMSCs increased the viability of chondrocytes following co-implantation in a osteo-chondral defects model. Co-implantation of BMSCs and chondrocytes may be a promising approach to repairing osteo-chondral defects in the clinical setting.
\end{abstract}

Correspondence to: Dr Xinshe Zhou, Department of Orthopedics, The First Affiliated Hospital of Bengbu Medical College, Anhui Key Laboratory of Tissue Transplantation, 287 Changhuai Road, Bengbu, Anhui 233004, P.R. China

E-mail: xinshezhou226@sina.com

Key words: co-culture, mesenchyaml stem cells, chondrocytes, osteochondral defects, knee injury

\section{Introduction}

Cartilage is an important connective tissue that exists in the muscle-skeleton system, particularly in joints, rib, ear, nose, bronchial tubes and intervertebral discs (1). It's generally believed that cartilage contains only one cell type called chondrocyte that produces all cartilage extracellular matrix consisting of Type II collagen in articular cartilage or mixture of type I and type II collagen in fibrocartilage (2). Since cartilage is avascularized, the metabolic activity of chondrocytes is low, compared with other connective tissues (3). Nutrition of chondrocytes is supplied by diffusion, by the pumping action generated by compression of the articular cartilage during extension or flexion of joints (3). Furthermore, chondrocytes are embedded in spaces called lacunae, which keeps them from migrating to damaged areas. Therefore, the self-repair ability of damaged cartilage is limited (4). Over the last decades, stem cell based technology has been proposed for cartilage repair joint injury (reviewed in 5). Especially when bone marrow mesenchymal stem cells (BMSCs) were demonstrated to be able to differentiate into chondrocytes, these were immediately considered as the ideal source for engineering cartilage tissue (5).

However, novel findings uncovered other properties of BMSCs rather than differentiation into specific cell types. One of the most important is the trophic role of BMSCs in tissue repair $(4,5)$. As first introduced, the terminology 'trophic' initially referred to non-neurotransmitter bioactive molecules produced by nerve terminals (6). Specifically, 'trophic' was first used to describe the process in which BMSCs secrete factors stimulating neighboring cells to release functionally bioactive molecules (7). This term also relates to the effect of the factors produced by BMSC on viability, proliferation, and matrix production of the neighboring cells. This supportive effect of BMSCs on other cells types significantly broadened the application of BMSCs in regenerative medicine. While traditionally it was believed that BMSCs mainly repair damaged tissue by differentiating into specific cell types and replacing lost cells (8), nowadays the trophic role of the BMSCs in tissue repair is considered more important than before (9).

The use of BMSCs to partially replace chondrocytes may reduce the number of chondrocytes necessary for autologous 
chondrocytes transplantation (ACT). In previously published papers, pellet co-culture models of chondrocytes and bone marrow derived BMSCs were employed to study the beneficial effects of co-culture on cartilage matrix formation (10-12). In these pellet co-cultures, it had been demonstrated that cartilage matrix was mainly produced by chondrocytes but not BMSCs. These studies revealed a new mechanism of cross-talk between cells in a co-culture model of BMSCs and chondrocytes. Studies indicated that the beneficial effects on cartilage matrix formation in co-culture pellets were due to trophic effects of BMSCs which stimulated chondrocyte proliferation and cartilage matrix deposition. Studies also demonstrated that these trophic effects are independent of culture conditions and BMSCs sources (11). Notably, it's been identified in all these studies that the ratio of BMSCs decreased dramatically due to BMSCs death and proliferation of chondrocytes in co-culture. However, none of the published studies actually tracked the fate of BMSCs or chondrocytes following co-implantation in osteo-chondral defect models $(6,7,9,10)$.

In the present study, the destiny of BMSCs and chondrocytes in co-culture pellets and in co-implantation of an osteo-chondral defect model was investigated. Data revealed that BMSCs increased the viability of chondrocytes in co-implantation in an osteo-chondral defect model.

\section{Materials and methods}

Cell culture. The use of experimental animals in the present study was approved by the Medical Ethical Committee of the First Affiliated Hospital of Bengbu Medical College (Bengbu, China). Primary chondrocytes were obtained from knee joints of 12 neonatal Sprague Dawley rats, all male, aged 8 weeks. The rats were kept in 12 -h light/dark cycle at $37^{\circ} \mathrm{C}$ and a humidity of $40 \%$ and had free access to water and food. The rats were anaesthetized with isoflurane at a dosage of 1-3\%, as previously describe (13). Cartilage biopsies were digested for $20-22 \mathrm{~h}$ in collagenase type II ( $0.15 \%$ Worthington, NJ, US) dissolved in medium containing DMEM supplemented with 10\% FBS (Gibco; Thermo Fisher Scientific, Inc., Waltham, MA, USA.) and antibiotics (100 U/ml penicillin and $100 \mu \mathrm{g} / \mathrm{ml}$ streptomycin; basic medium) as previously described (14). BMSCs were isolated from the bone marrow of neonatal rats previously reported $(13,14)$. BMSCs were seeded in culture flasks with basic medium. Media were replaced every 2 days to remove floating cells. When $90 \%$ confluent, cells were digested with trypsin and passaged. The cells cultured on culture plastic were cultured to passage 2 prior to use. All reagents used for cell culture were purchased from Gibco (Thermo Fisher Scientific, Inc.). Common chemicals were purchased from Sigma-Aldrich; Merck KGaA, Darmstadt, Germany.

Pellet culture and chondrogenic culture. For mono-cultures, 200,000 primary chondrocytes or BMSCs were seeded in one well of a round bottom 96 wells plate (non-tissue culture treated). For co-cultures, 200,000 chondrocytes or BMSCs were seeded at 1:1 ratio. Cells were initially seeded in basic medium and centrifuged at $37^{\circ} \mathrm{C}$ for $5 \mathrm{~min}$ at $500 \mathrm{x} \mathrm{g}$. Medium was changed to chondrogenic differentiation medium (DMEM supplemented with $40 \mu \mathrm{g} / \mathrm{ml}$ of proline, $50 \mathrm{ug} / \mathrm{ml}$ ITS-premix, $50 \mathrm{ug} / \mathrm{ml}$ of AsAP, $100 \mathrm{ug} / \mathrm{ml}$ of Sodium Pyruvate, $10 \mathrm{ng} / \mathrm{ml}$ of TGF $\beta 3,10^{-7} \mathrm{M}$ of dexamethasone, $500 \mathrm{ng} / \mathrm{ml}$ of BMP6, $100 \mathrm{U}$ penicillin $/ \mathrm{ml}$ and $100 \mu \mathrm{g} / \mathrm{ml}$ streptomycin) one day following seeding and stable pellets were formed. Cell pellets were cultured for 4 weeks prior to analysis.

GAG staining. Cell pellets for co-cultures were fixed with $10 \%$ formalin for $28 \mathrm{~h}$, decalcified, dehydrated and embedded in paraffin using routine procedures (14). A microtome (Thermo Fischer Scientific, Inc.) was used to cut $5 \mu \mathrm{m}$ thick sections. Slides were then deparaffinized and stained for sulfated glycosaminoglycans (GAG) with Toluidine blue for $2 \mathrm{~h}$ at $37^{\circ} \mathrm{C}$.

Quantitative GAG and DNA content assays. Cell pellets were washed with PBS and stored at $-80^{\circ} \mathrm{C}$ for $16-20 \mathrm{~h}$. Subsequently, they were digested with proteinase $\mathrm{K}$ solution [ $1 \mathrm{mg} / \mathrm{ml}$ proteinase $\mathrm{K}$ in Tris/EDTA buffer ( $\mathrm{pH}$ 7.6)] for $>16 \mathrm{~h}$ at $56^{\circ} \mathrm{C}$. GAG content was spectrophotometrically determined with 1,9-dimethylmethylene blue chloride (DMMB) staining for $2 \mathrm{~h}$ at $37^{\circ} \mathrm{C}$ in PBE buffer $\left(14.2 \mathrm{~g} / 1 \mathrm{Na}_{2} \mathrm{HPO}_{4}\right.$ and $3.72 \mathrm{~g} / \mathrm{l}$ $\mathrm{Na}_{2}$ EDTA, $\mathrm{pH}$ 6.5) using a microplate reader (TECAN group, Ltd., Mannedorf, Switzerland) at an absorbance of $520 \mathrm{~nm}$ using standard curves generated with chondroitin sulfate. Total DNA content was determined using a CyQuant DNA Kit (Molecular Probes; Thermo Fisher Scientific, Inc.).

$D N A$ isolation and reverse transcription-quantitative polymerase chain reaction ( $R T-q P C R)$. DNA samples from cell pellets were isolated with DNeasy Mini Kit (Qiagen GmbH, Hilden, Germany). Total genomic RNA was used for RT-qPCR using the iQ SYBR Green Supermix (Bio-Rad Laboratories, Inc., Hercules, CA, USA). PCR Reactions were carried out on MyiQ2 Two-Color Real-Time PCR Detection System (Bio-Rad, Laboratories, Inc.) under the following conditions: cDNA was denatured for $5 \mathrm{~min}$ at $95^{\circ} \mathrm{C}$, followed by 45 cycles, consisting of $15 \mathrm{sec}$ at $95^{\circ} \mathrm{C}, 15 \mathrm{sec} 60^{\circ} \mathrm{C}$ and $30 \mathrm{sec}$ at $72^{\circ} \mathrm{C}$. For each reaction, a melting curve was generated to test primer dimer formation and non-specific amplification. Primer sequences were as follows: Green fluorescence protein (GFP) Forward, 5'-ACGACGGCAACTACAAGA CC-3' and Reverse, 5'-TTGTACTCCAGCTTGTGCCC-3'; red fluorescence protein (RFP) Forward, 5'-AAGCTGAAG GTGACCAAGGG-3' and Reverse, 5'-CAAGTAGTCGGG GATGTCGG-3'; GAPDH Forward, 5'-GATGGTGAAGGT CGGTGTGA-3' and Reverse, 5'-TTCTCAGCCTTGACTGTG CC-3'. Relative gene copies were calculated using the $2^{-\Delta \Delta C q}$ method (15). GAPDH was used for normalization.

Rat osteochondral defect model. Twelve athymic nude rats (all male) of 8-weeks old, weighing 25-30 g, were kept in 12-h light/dark cycle at a temperature of $37^{\circ} \mathrm{C}$ and a humidity of $40 \%$ and had free access to water and food. They were anaesthetized with isoflurane with dosage of 1-3\% and a medial parapatellar incision was made so that the knee joint was exposed. The patella was dislocated laterally and the anterior articular surface of the distal femur was exposed. A 1-mm-diameter full-thickness cylindrical osteochondral defect was made using an electrical trephine in the articular surface of the femoral patellar groove. Then 200,000 cell pellets were put into the defects. Suturing the knee joint capsule and the skin layer-by-layer closed the wound. Rats were allowed to 
move freely following surgery. Each rat carried one pellet. Pellets made of BMSCs or chondrocytes, or co-cultures were implanted into the three experimental groups, containing 4 rats per group. All samples were used for histological staining.

Cell tracking with green and red fluorescence proteins. To track cells in co-cultures and co-implantation, BMSCs were labeled with red fluorescence protein by lenti-viral transduction, while chondrocytes were labeled with green fluorescence protein. Lenti-GFP and Lenti-RFP virus were purchased from lenti-virus were carried out by Hanbio biotechnology, Co, Ltd. (Shanghai, China). Both lenti-viral vectors contained resistant genes against puromycin. Infection of cells with Lenti-GFP or Lenti-RFP (4\%) was performed in $1.0 \mathrm{ml}$ of serum-free basic medium for $4 \mathrm{~h}$ at $37^{\circ} \mathrm{C}$. Following infection, the remaining supernatant was removed and replaced with basic medium supplemented with $10 \%$ fetal bovine serum. Stably transduced cells were selected by adding puromycin $(1 \mu \mathrm{g} / \mathrm{ml})$ in culture medium on day 2 following infection. Antibiotic selection lasted for 1 week. Selection efficiency was verified by visual examination under a fluorescence microscope. To examine GFP and RFP signals in co-culture pellets, cryosections were made with a cryotome (Leica CM1520, Leica Microsystems GmbH, Wetzlar, Germany).

Immunofluorescence staining. For immunocytochemistry, sections of co-culture pellets of BMSCs and chondrocytes were deparaffinized, incubated with $3 \%$ hydrogen peroxide and blocked in $1 \%$ bovine serum albumin and $1.5 \%$ normal goat serum at $37^{\circ} \mathrm{C}$. Slides were subsequently incubated overnight at $4^{\circ} \mathrm{C}$ with mouse monoclonal antibodies against GFP (GF28R; Novagen; Merck KGaA) or RFP (cat no. 69831-3; Novagen; Merck KGaA). Sequentially, primary antibodies were visualized by incubating with fluorochrome-labeled secondary antibodies at $37^{\circ} \mathrm{C}$ (L21998; Invitrogen; Thermo Fisher Scientific, Inc). Counterstaining was performed with DAPI under a light microscope (Olympus IX51; Olympus Corporation, Tokyo, Japan).

Statistical analysis. Statistical significance between different groups was examined with one-way analysis of variance followed by Tukey Honestly Significant Difference Test. All data were presented as the mean \pm standard deviation. $\mathrm{P}<0.05$ was considered to indicate a statistically significant difference.

\section{Results}

Isolation and labeling of rat BMSCs and chondrocytes. Articular chondrocytes were isolated from knee joints of neonatal rats. Following in vitro expansion for two passages, cells displayed a typical morphology of chondrocytes (Fig. 1). Chondrocytes first spread in a bipolar fashion for a few days, then most cells displayed polygonal morphology with few filopodia. BMSCs presented a spindle-like shape. With time in culture, cells gradually adopted a more fibroblastic morphology (Fig. 1). With lenti-virus infection, chondrocytes were labeled with GFP while BMSCs were labeled with RFP. Both cells were selected by puromycin for 1 week prior to reaching a labeling efficiency closing to $100 \%$, as examined by fluorescent microscope (Fig. 1).
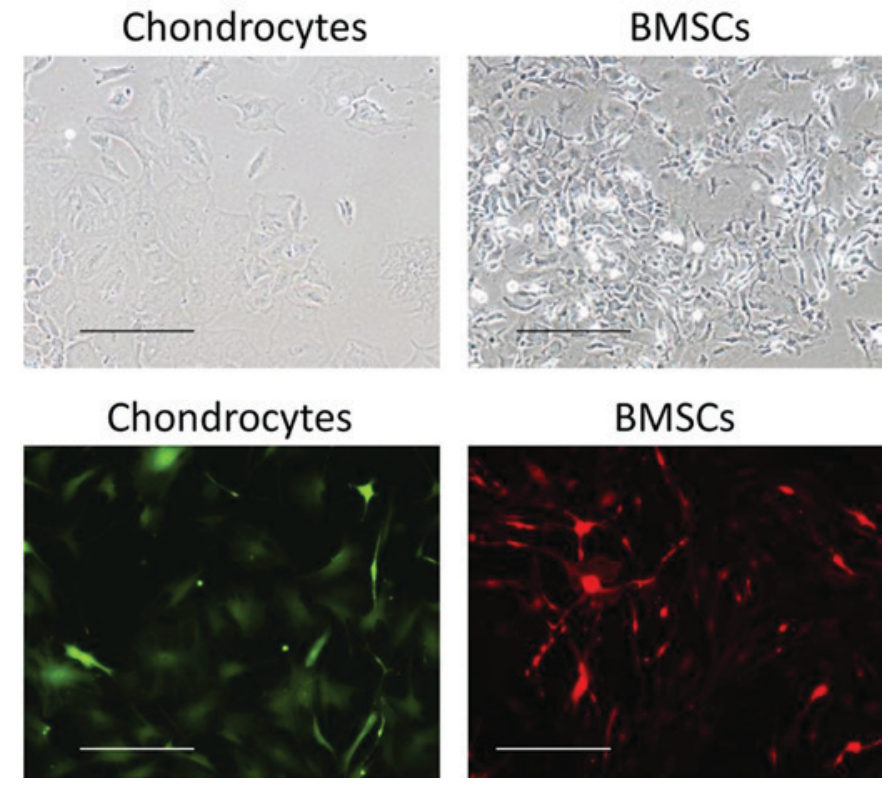

Figure 1. Morphology of rat chondrocytes and bone marrow mesenchymal stem cells. Phase contrast images were taken from passage 2 of chondrocytes and BMSCs. Rat chondrocytes and BMSCs were labeled with GFP and RFP respectively. Scale bar $=100 \mu \mathrm{m}$. BMSCs, bone marrow mesenchymal stem cells; GFP, green fluorescence protein; RGP, red fluorescence protein.

Co-culture pellets deposited more GAGs and collagen than mono-cultures pellets. Labeled chondrocytes and BMSCs were used to make cartilage tissue in pellet cultures. Four weeks following seeding, cell pellets of both mono- and co-culture were harvested for histology, GAG assay. As demonstrated in Fig. 2A, BMSCs pellets were able to deposit some GAG into extracellular matrix. Chondrocytes pellets, however, deposited much more GAG than BMSCs. When co-cultured, chondrocytes and BMSCs together produced extracellular matrix containing abundant GAG in the pellets which was significantly more than that in mono-culture pellets, as measured by toluidine blue staining (Fig. 2B). The same was observed in the collagen assay by quantifying hydroxyproline (Fig. 2C).

BMSCs and chondrocytes in co-cultures. To track BMSCs and chondrocytes following co-culture, cryosections were made to examine GFP and RFP signals in the pellets, 1 week after the pellets were made. As depicted in Fig. 3A, both RFP and GFP positive cells were present in co-culture pellets. RFP labeled BMSCs tended to present in the center of the pellets, while GFP labeled chondrocytes were distributed more on the periphery of the pellet. Subsequently, RT-qPCR was performed to track RFP and GFP DNA contents in them. Compared with the cells initially seeded (week 0), the RFP positive cells dropped following 1 week of co-culture to roughly $80 \%$, continued to decrease until week 3 and kept stable at week 4 at about $15 \%$ (Fig. 3B). On the other hand, GFP positive cells increased at week 1 to about $120 \%$ of week 0 , and remained stable thereafter (Fig. 3C).

Effect of BMSCs on the survival rate of chondrocytes following co-implantation in rat osteo-chondral defect model. To test the viability of cells following implantation into osteo-chondral defects, pellets made of BMSCs, chondrocytes or co-cultures 


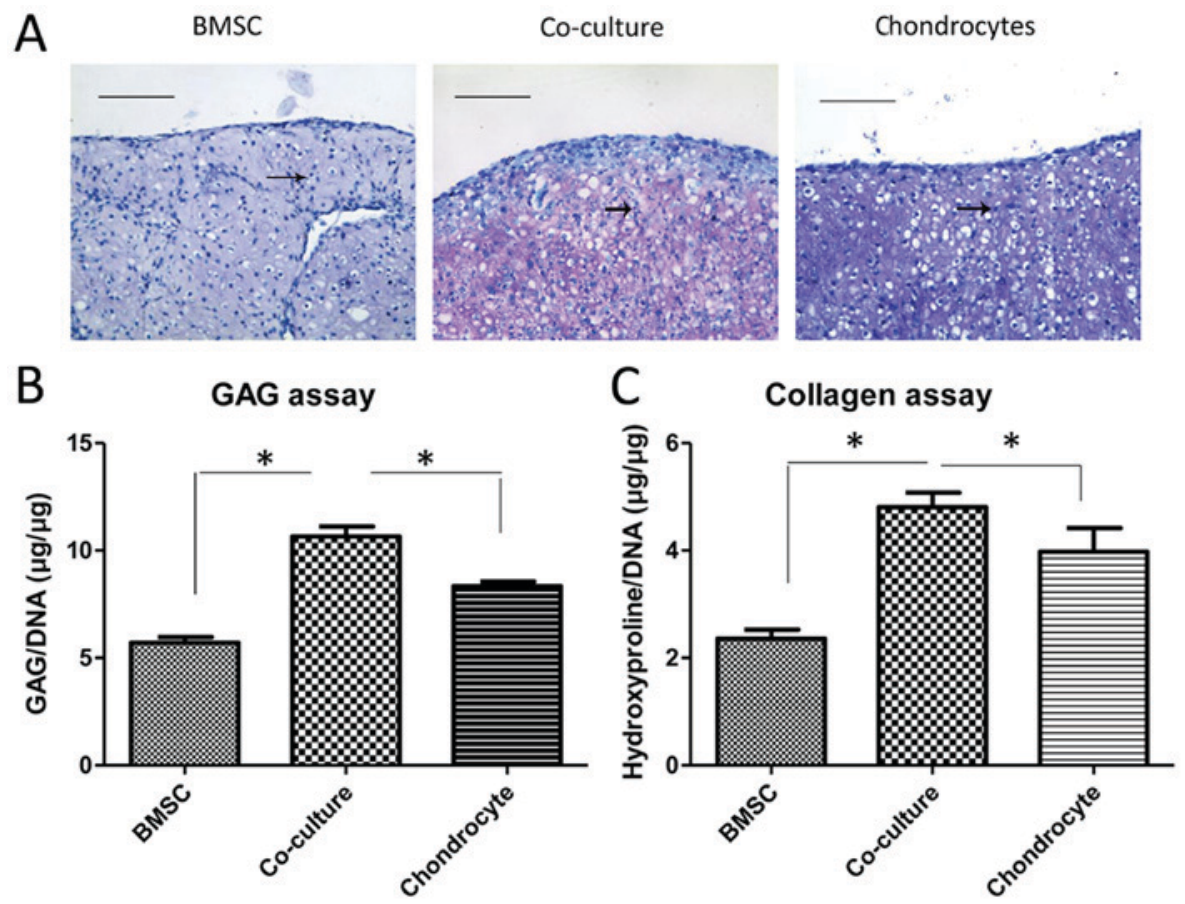

Figure 2. Co-culture of chondrocytes and BMSCs increase cartilage matrix formation. (A) Toluidine blue staining was performed at week 4 following chondrogenic differentiation. Scale bar $\mathrm{r}=100 \mu \mathrm{m}$. (B) Quantitative GAG assay demonstrated more GAG in co-culture group than other two groups at week 4 . (C) Collagen contents were quantified with hydroxyproline assay. Data are presented as the mean \pm standard deviation. ${ }^{*} \mathrm{P}<0.01$ co-culture group vs. other two groups. BMSCs, bone marrow mesenchymal stem cells; GAG, sulfated glycosaminoglycans.
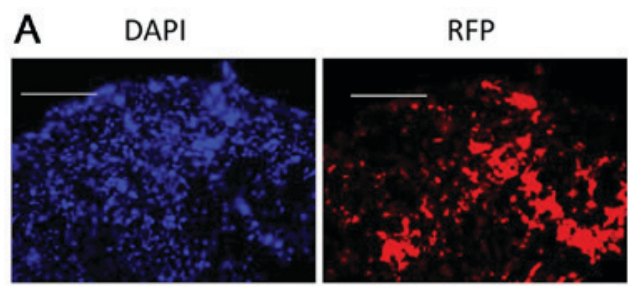

B

BMSCs

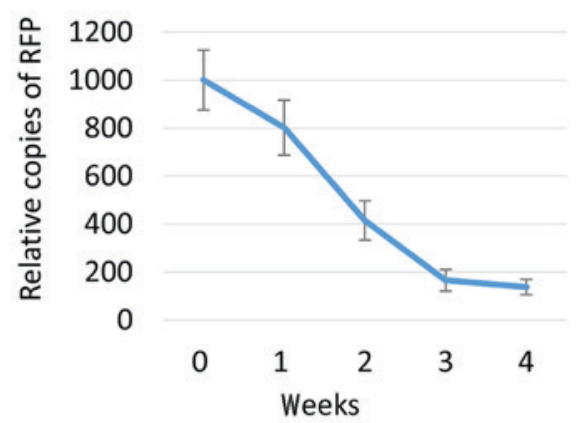

GFP

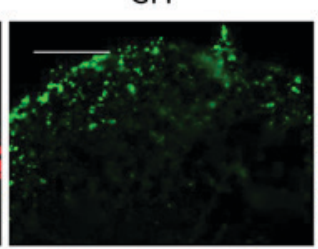

C

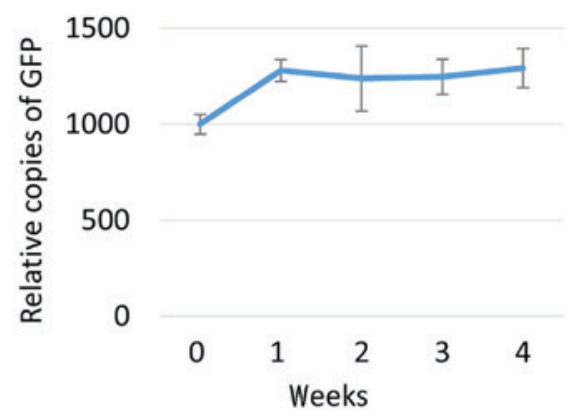

Figure 3. BMSCs were overtaken by chondrocytes in co-culture pellets. (A) Cryosections were made to examine the red and green signals carried by BMSCs and chondrocytes. Scale bar $=100 \mu \mathrm{m}$. (B) RT-qPCR was performed to measure the relative copies of RFP to represent BMSCs in co-culture pellets. (C) Relative copies of GFP were calculated to represent chondrocytes in co-culture pellets. BMSCs, bone marrow mesenchymal stem cells; GFP, green fluorescence protein; RGP, red fluorescence protein.

were implanted into a nude rat knee injury model. Cell tracking by DNA content using GFP and RFP indicated that a few BMSCs survived in defects when implanted alone (Fig. 4A). In one section, less than 40 cells were found to be red in the defect area (Fig. 4B). Chondrocytes however, survived compared with BMSCs when implanted alone into the defects, with about 80 cells labeled with green in one section. Notably, the viability of BMSCs in co-culture pellets was extremely low, with roughly 4 cells found in defect area (Fig. 4C).

\section{Discussion}

In recent years, trophic effects of BMSCs have attracted much attention in cartilage engineering (reviewed in 16). 

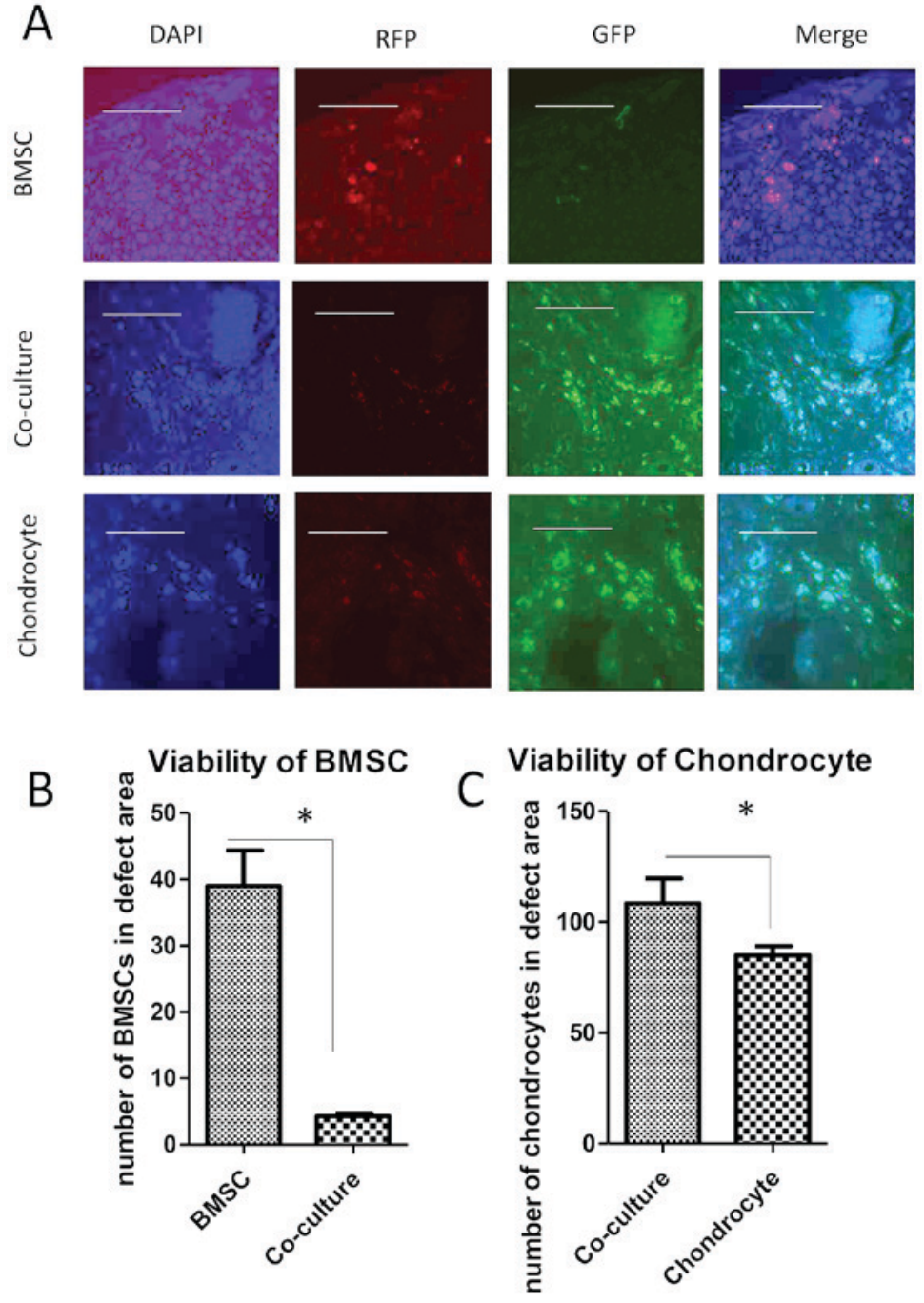

Figure 4. BMSCs increased the viability of chondrocytes after co-implantation in a rat osteo-chondral defect. (A) Immunofluorescent staining was used to track BMSCs and chondrocytes after implantation at week 4. Scale bar $=200 \mu \mathrm{m}$. (B and C) Viable BMSCs or chondrocytes were counted with immunofluorescent images. Data are presented as the mean \pm standard deviation. ${ }^{*} \mathrm{P}<0.01$ co-culture vs. other two groups. BMSCs, bone marrow mesenchymal stem cells; GFP, green fluorescence protein; RGP, red fluorescence protein.

However, very few studies successfully revealed the viability of BMSCs or chondrocyte after co-implantation into osteo-chondral defects $(13,15)$. In the present study, BMSCs and chondrocytes were labeled with fluorescence proteins and were tracked in pellet co-cultures and in a osteo-chondral defect model.

Multiple studies have investigated the effects of BMSCs on chondrocytes (13-15), but few have provided data to indicate the viability of BMSCs and chondrocytes in the content of direct cell-cell contact neither in vitro nor in vivo (13-16). The present study demonstrated that co-culture of BMSCs and chondrocytes led to a decrease in BMSCs cell numbers which can be explained by reduced cell proliferation or cell death, but this needs to be confirmed. Since previous study demonstrated massive cell death of BMSCs by apoptosis (10). The decrease of BMSCs numbers following 1 week of co-culture may suggest that chondrocytes were able to change their behavior. Similar results have been demonstrated in studies using co-culture of BMSCs with chondrocyte pellets from different sources, during 3 to 4 weeks of culture, in which BMSCs numbers decreased progressively $(17,18)$. Besides the dramatic decrease of BMSCs following co-culture, the proliferation of chondrocytes demonstrated a trend of slowdown of the increasing rate following one week of co-culture. In fact, in a previous study employing a pellet co-culture system of BMSCs and chondrocytes, an increase in chondrogenic markers was observed at later stage of culture, following day 7 (19). This is in line with the present finding that proliferation of chondrocytes occurred in the first week of co-culture (20).

A previous report demonstrated that significant numbers of TUNEL positive BMSCs were detected in co-culture pellets (21). This result suggests that the BMSCs may have died by apoptosis upon contacting with chondrocytes. This may have occurred due to cell compaction, and nutrition or space limitation in pellets. The cell labeling experiments demonstrated that the majority of BMSCs reside in the center while most chondrocytes presented on the edge of the pellets. BMSCs may undergo apoptosis simply due to lack of nutrients or oxygen, which was more likely to happen in the center of the pellet (22). However, this is not sufficient to explain why the number of BMSCs deceased so much since some of BMSCs 
did survive in the middle of a pellet made by BMSCs alone. This suggested that besides to location of BMSCs in pellets, the presence of chondrocytes may have also contributed to the apoptosis of BMSCs. It's known that chondrocytes may secrete some apoptotic cytokines (23), which may have induced the death of BMSCs, but his needs to be further confirmed. Furthermore, it is likely that direct cell-cell contact between chondrocytes and BMSCs may have contributed to increased cell death (24).

Viability of cells in tissue engineering is an important issue for regenerative medicine (25). The present data indicated that viability of chondrocytes increased a lot with co-implantation compared with chondrocyte implanted alone, despite the death of BMSCs. A lot of factors are involved in the death of chondrocytes during autologous chondrocyte transplantation into joint environment (26). Mechanical stress, low oxygen and lack of nutrients may cause apoptosis or necrosis of chondrocytes. Small chemicals and bio-compatible scaffolds are designed to increase the viability of chondrocytes $(27,28)$. Findings of the present study may provide an alternative solution to reduce the cell death of chondrocytes after implantation, which is mixing chondrocytes with BMSCs. This may benefit the matrix deposition, but also increase chondrocytes viability, but this needs to be studied further.

To conclude, the present data indicated that BMSCs were overtaken by chondrocytes in the pellet co-culture. Results from the in vivo study demonstrated that BMSCs increased the viability of chondrocytes following implantation in osteo-chondral defects. Co-implantation of BMSCs and chondrocytes may be a promising procedure in repairing osteo-chondral defects in clinical settings.

\section{Acknowledgements}

Not applicable.

\section{Funding}

The present study was funded by a seed grant for scientific innovation from Bengbu Medical College (Bengbu, Anhui, China).

\section{Availability of data and materials}

The datasets generated and analyzed during the current study are not publicly available due to statutory provisions regarding data and privacy protection, the dataset supporting the conclusions of this article is available upon reasonable request directed to the corresponding author.

\section{Authors' contributions}

$\mathrm{ZZ}, \mathrm{XZ}$ and JG were involved in the conception and design of the study, in the collection, assembly, analysis and interpretation of the data, and in drafting of the article; they also provided statistical expertise. JZ, MW and ZZ contributed to final approval of the article, provision of study materials, and administrative, technical and logistical support, as well as critical revision of the article for important intellectual content.

\section{Ethics approval and consent to participate}

The use of experimental animals in the present study was approved by the Medical Ethical Committee of the First Affiliated Hospital of Bengbu Medical College (Bengbu, China).

\section{Consent for publication}

Not applicable.

\section{Competing interests}

The authors declare that they have no competing interests.

\section{References}

1. Ulrich-Vinther M, Maloney MD, Schwarz EM, Rosier R and O'Keefe RJ: Articular cartilage biology. J Am Acad Orthop Surg 11: 421-430, 2003.

2. Mollenhauer JA: Perspectives on articular cartilage biology and osteoarthritis. Injury 39 (Suppl 1): S5-S12, 2008.

3. Lee DA, Salih V, Stockton EF, Stanton JS and Bentley G: Effect of normal synovial fluid on the metabolism of articular chondrocytes in vitro. Clin Orthop Relat Res: 228-238, 1997.

4. Umlauf D, Frank S, Pap T and Bertrand J: Cartilage biology, pathology, and repair. Cell Mol Life Sci 67: 4197-4211, 2010.

5. Schindler OS: Current concepts of articular cartilage repair. Acta Orthop Belg 77: 709-726, 2011.

6. Singer M: Trophic functions of the neuron. VI. Other trophic systems. Neurotrophic control of limb regeneration in the newt. Ann N Y Acad Sc 228: 308-322, 1974.

7. Caplan AI and Dennis JE: Mesenchymal stem cells as trophic mediators. J Cell Biochem 98: 1076-1084, 2006.

8. Bruder SP, Fink DJ and Caplan AI: Mesenchymal stem cells in bone development, bone repair, and skeletal regeneration therapy. J Cell Biochem 56: 283-294, 1994.

9. Kassis I, Vaknin-Dembinsky A and Karussis D: Bone marrow mesenchymal stem cells: Agents of immunomodulation and neuroprotection. Curr Stem Cell Res Ther 6: 63-68, 2011.

10. Wu L, Leijten JC, Georgi N, Post JN, van Blitterswijk CA and Karperien M: Trophic effects of mesenchymal stem cells increase chondrocyte proliferation and matrix formation. Tissue Eng Part A 17: 1425-1436, 2011.

11. Wu L, Prins HJ, Helder MN, van Blitterswijk CA and Karperien M: Trophic effects of mesenchymal stem cells in chondrocyte co-cultures are independent of culture conditions and cell sources. Tissue Eng Part A 18: 1542-1551, 2012.

12. Acharya C, Adesida A, Zajac P, Mumme M, Riesle J, Martin I and Barbero A: Enhanced chondrocyte proliferation and mesenchymal stromal cells chondrogenesis in coculture pellets mediate improved cartilage formation. J Cell Physiol 227: 88-97, 2012.

13. Jurgens WJ, Oedayrajsingh-Varma MJ, Helder MN, Zandiehdoulabi B, Schouten TE, Kuik DJ, Ritt MJ and van Milligen FJ: Effect of tissue-harvesting site on yield of stem cells derived from adipose tissue: Implications for cell-based therapies. Cell Tissue Res 332: 415-426, 2008.

14. Lee SY, Nakagawa T and Reddi AH: Mesenchymal progenitor cells derived from synovium and infrapatellar fat pad as a source for superficial zone cartilage tissue engineering: Analysis of superficial zone protein/lubricin expression. Tissue Eng Part A 16: 317-325, 2010.

15. Livak KJ and Schmittgen TD: Analysis of relative gene expression data using real-time quantitative PCR and the 2(-Delta Delta C(T)) method. Methods 25: 402-408, 2001.

16. Stoddart MJ, Bara J and Alini M: Cells and secretome-towards endogenous cell re-activation for cartilage repair. Adv Drug Deliv Rev 84: 135-145, 2015.

17. Song X, Xie Y, Liu Y, Shao M and Wang W: Beneficial effects of coculturing synovial derived mesenchymal stem cells with meniscus fibrochondrocytes are mediated by fibroblast growth factor 1: Increased proliferation and collagen synthesis. Stem Cells Int 2015: 926325, 2015. 
18. Lai JH, Rogan H, Kajiyama G, Goodman SB, Smith RL, Maloney W and Yang F: Interaction between osteoarthritic chondrocytes and adipose-derived stem cells is dependent on cell distribution in three-dimension and transforming growth factor- $\beta 3$ induction. Tissue Eng Part A 21: 992-1002, 2015.

19. Aung A, Gupta G, Majid G and Varghese S: Osteoarthritic chondrocyte-secreted morphogens induce chondrogenic differentiation of human mesenchymal stem cells. Arthritis Rheum 63: 148-158, 2011.

20. Mardones R, Jofré CM and Minguell JJ: Cell therapy and tissue engineering approaches for cartilage repair and/or regeneration. Int J Stem Cells 8: 48-53, 2015.

21. Meretoja VV, Dahlin RL, Wright S, Kasper FK and Mikos AG: Articular chondrocyte redifferentiation in $3 \mathrm{D}$ co-cultures with mesenchymal stem cells. Tissue Eng Part C Methods 20: 514-523, 2014.

22. Yao L, Pike SE, Pittaluga S, Cherney B, Gupta G, Jaffe ES and Tosato G: Anti-tumor activities of the angiogenesis inhibitors interferon-inducible protein-10 and the calreticulin fragment vasostatin. Cancer Immunol Immunother 51: 358-366, 2002.

23. Secchiero P, Melloni E, Corallini F, Beltrami AP, Alviano F, Milani D, D'Aurizio F, di Iasio MG, Cesselli D, Bagnara GP and Zauli G: Tumor necrosis factor-related apoptosis-inducing ligand promotes migration of human bone marrow multipotent stromal cells. Stem Cells 26: 2955-2963, 2008.
24. Song IH, Caplan AI and Dennis JE: Dexamethasone inhibition of confluence-induced apoptosis in human mesenchymal stem cells. J Orthop Res 27: 216-221, 2009.

25. Guthrie K, Bruce A, Sangha N, Rivera E and Basu J: Potency evaluation of tissue engineered and regenerative medicine products. Trends Biotechnol 31: 505-514, 2013.

26. Hindle P, Hall AC and Biant LC: Viability of chondrocytes seeded onto a collagen I/III membrane for matrix-induced autologous chondrocyte implantation. J Orthop Res 32: 1495-1502, 2014

27. Liu Q, Lu Z, Wu H and Zheng L: Chondroprotective effects of taurine in primary cultures of human articular chondrocytes. Tohoku J Exp Med 235: 201-213, 2015.

28. Shui W, Yin L, Luo J, Li R, Zhang W, Zhang J, Huang W, Hu N, Liang X, Deng ZL, et al: Characterization of chondrocyte scaffold carriers for cell-based gene therapy in articular cartilage repair. J Biomed Mater Res A 101: 3542-3550, 2013.

(i) $\ominus$ This work is licensed under a Creative Commons Attribution-NonCommercial-NoDerivatives 4.0 International (CC BY-NC-ND 4.0) License. 